\title{
Recurrent Spontaneous Miscarriage Is Still a Challenging Diagnostic and Therapeutic Quagmire
}

\author{
Michael F.E. Diejomaoh \\ Department of Obstetrics and Gynaecology, Faculty of Medicine, Kuwait University, and Maternity Hospital, \\ Kuwait City, Kuwait
}

\section{Key Words}

Recurrent spontaneous miscarriage - Aetiology of recurrent spontaneous miscarriage - Antiphospholipid syndrome .

Disease management - Parental karyotype disorder .

Uterine anatomic abnormality

\section{Abstract}

Recurrent spontaneous miscarriage (RSM), affecting $1-2 \%$ of women of reproductive age seeking pregnancy, has been a clinical quagmire and a formidable challenge for the treating physician. There are many areas of controversy in the definition, aetiology, investigations and treatment of RSM. This review will address the many factors involved in the aetiology of RSM which is multifactorial in many patients, with antiphospholipid syndrome (APS) being the most recognized aetiological factor. There is no identifiable cause in about $40-60 \%$ of these patients, in which case the condition is classified as idiopathic or unexplained RSM. The RSM investigations are extensive and should be undertaken in dedicated, specialized, well-equipped clinics/centres where services are provided by trained specialists. The challenges faced by

\section{KARGER 125}

E-Mail karger@karger.com www.karger.com/mpp
(C) 2014 S. Karger AG, Basel

This is an Open Access article licensed under the terms of the Creative Commons Attribution-NonCommercial 3.0 Unported license (CC BY-NC) (www.karger.com/OA-license), applicable to the online version of the article only. Distribution permitted for non-commercial purposes only. the treating physician are even more overwhelming regarding the decision of what should be the most appropriate therapy offered to patients with RSM. Our review will cover the diverse modalities of therapy available including the role of preimplantation genetic testing using recent microarray technology, such as single nucleotide polymorphism and comparative genomic hybridization, as well as preimplantation genetic diagnosis; the greatest emphasis will be on the treatment of APS, and there will be important comments on the management of patients presenting with idiopathic RSM. The controversial areas of the role of natural killer cells in RSM, the varied modalities in the management of idiopathic RSM and the need for better-planned studies will be covered as well.

(c) 2014 S. Karger AG, Basel

\section{Introduction}

Recurrent spontaneous miscarriage (RSM) has been defined in a variety of ways by researchers and clinicians; different gestational ages and different numbers of previ-

Prof. Michael F.E. Diejomaoh

Department of Obstetrics and Gynaecology

Faculty of Medicine, Kuwait University

PO Box 24923, Safat 13110 (Kuwait)

E-Mail Michael@hsc.edu.kw 
ous miscarriages have been given in their definitions, even emphasizing the fact that the miscarriages may have originated from the same biological father [1-10]. This discrepancy and the lack of universal uniformity in the definition of RSM are challenging and create difficulties for researchers and clinicians in the comparative assessment of the outcome of their research and in patient care. Some authors quote the age of fetal viability or a gestational age of 24 weeks or less in defining recurrent miscarriage [5], others regard recurrent miscarriage as the loss of 2 or more consecutive pregnancies [11, 12]. In this review, RSM is defined as the loss of 3 or more consecutive pregnancies before 20 weeks' gestation, a definition that has been widely adopted $[1-4,6,7,10,13,14]$. It is pertinent to state here that in our practice in Kuwait, we do commence RSM investigations in patients 35 years and older who have had 2 or more previous consecutive miscarriages because of the decline in fertility with increasing maternal age.

RSM is synonymous with recurrent spontaneous abortion and recurrent pregnancy loss, terminologies which are used by other authors [1, 3-5, 7, 10-12]. RSM affects women in the first and second trimesters of pregnancy. The incidence of RSM in women of reproductive age seeking pregnancies is reported to be $1-2 \%[1-3,6,13$, 14]. RSM, which is distressing to the affected families [13] and the couple seeking parenthood, has been a formidable challenge for the treating physician [15]; it has also been regarded as a heartbreaking and frustrating condition [16]. Patients presenting with RSM have experienced psychological trauma as they face the uncertainty of the outcome of the next pregnancy, and a variety of psychological and psychiatric disorders including anxiety, depression, posttraumatic stress disorders, and obsessivecompulsive disorders develop in these patients after RSM [17].

A patient who has RSM without a previous ongoing pregnancy (viable pregnancy) beyond 20 weeks' gestation is defined as presenting with 'primary RSM'. Those patients who present with an episode of RSM after 1 or more previous pregnancies (viable pregnancies) beyond 20 weeks' gestation are said to present with 'secondary RSM'. Tertiary RSM occurs after an episode of secondary RSM. The probabilities of live births after episodes of primary and secondary RSM are estimated at 50 and 70\%, respectively. Maternal and fetal morbidity may also be different.
Table 1. Aetiology of RSM

\begin{tabular}{|c|c|c|}
\hline & Genetic factors & $3-5 \%$ \\
\hline & Anatomical factors & \\
\hline & Cervical incompetence & \} $1-28 \%$ \\
\hline & Infective factors & \\
\hline & Endocrine factors & \\
\hline & Thyroid dysfunction & \\
\hline & Diabetes mellitus & \\
\hline & Luteal phase deficiency & \\
\hline & PCOS & \\
\hline- & Autoimmune factors/APS ${ }^{1}$ & \\
\hline & Thrombophilic defects & \\
\hline & (congenital thrombophilias) & \\
\hline & Antithrombin III deficiency & \\
\hline & Protein $\mathrm{C} /$ protein $\mathrm{S}$ deficiency & \\
\hline & Activated protein $\mathrm{C}$ resistance & \\
\hline & Factor V Leiden & \\
\hline & Prothrombin G20210A & \\
\hline & MTHFR C677T polymorphisms & \\
\hline- & Alloimmune factors 1 & \\
\hline & Unexplained recurrent spontaneous miscarriage & $40-60 \%$ \\
\hline & Other aetiological factors & \\
\hline & Environmental factors/occupational factors & \\
\hline & Obesity & \\
\hline & Personal habits & \\
\hline & Smoking & \\
\hline & Alcohol consumption & \\
\hline & Caffeine & \\
\hline
\end{tabular}

${ }^{1}$ Immune-related aetiological factors.

\section{The Aetiology of RSM}

The aetiology of RSM may be multifactorial in many patients, with 2-3 different causes reported in the same patient $[1,3-5,15]$. In spite of the array of causes listed in table 1, there is still a huge challenge in identifying the causes of RSM in the patients who present to the clinics for investigation, especially as no cause may be identified in $40-60 \%$ of patients.

\section{General Risk Factors}

Some general risk factors have been established [1824]. Increasing maternal age has been associated with an increasing incidence of further or recurrent miscarriages $[18,19]$, which may not be unrelated to the decline in number and quality of remaining oocytes with an increasing number of pregnancies. An increasing number of previous miscarriages is also associated with a rising incidence of further miscarriages or recurrence [18-20]. The relationship between rising maternal age and the risk of 
Table 2. Relationship of maternal age with miscarriage

\begin{tabular}{ll}
\hline Age, years & Miscarriage rate, \% \\
\hline $12-19$ & 13 \\
$20-24$ & 11 \\
$25-29$ & 12 \\
$30-34$ & 15 \\
$35-39$ & 25 \\
$40-44$ & 51 \\
$\geq 45$ & 9 \\
\hline
\end{tabular}

From Nybo Andersen et al. [18].

further miscarriages are illustrated in table 2. Advanced paternal age has also been associated with an increasing incidence of recurrent miscarriages, related to the declining seminal quality with age [21]. Obesity has been associated with an increased risk of recurrent miscarriage, with rising levels of the body mass index being linked to a greater risk of further miscarriages [22-24]. The role and contribution of other risk factors such as personal habits like heavy smoking (paternal/maternal), high maternal alcohol consumption and high maternal caffeine intake, which have all been linked with an increased risk of miscarriages/recurrent miscarriages, cause a great quagmire for the treating physician [3-5], since the evidence may be controversial and conflicting and patients may not fully comply with the counselling of the physician to reduce these risk factors.

\section{Genetic Factors}

Genetic factors account for RSM in 3-5\% of patients and are illustrated in table 1 . The incidence of chromosomal abnormalities, usually in the form of balanced translocations or inversions, has been reported to be increased in couples with RSM [3] and is reported in 2-5\% of patients [25] with RSM where one of the partners carries a balanced reciprocal or Robertsonian translocation [26-29]. Balanced translocations are the most common chromosome anomalies linked with RSM [5]. Numerous genetic polymorphisms have been associated with RSM [30]. The incidence of chromosome abnormalities and the types of these abnormalities recorded vary in patients with sporadic miscarriages and RSM [25]. Whereas parental balanced translocations/inversions may be classified as genetic inheritable causes of RSM, other genetic causes of RSM may be described as non-inheritable, as recorded in patients who are chromosomally normal, in- cluding embryonic aneuploidy (where there may be an increase or decrease in chromosomes) [25, 31, 32]; there may also be duplications or deletions of genetic information within chromosomes or single gene mutations [32]. It has been observed that a majority of miscarriages have been recorded in chromosomally normal patients [25].

\section{Anatomical Factors}

A variety of uterine malformations has been associated with RSM although the evidence is rather uncertain [5, $32-34]$. A wide range of $1.8-37.6 \%$ for the prevalence of uterine anomalies has been reported in patients presenting with recurrent miscarriage $[33,34]$. The incidence of uterine anomalies has been reported to be higher in women with second-compared with first-trimester miscarriages; this finding may be related to cervical disorders/ weakness/malformations which are more frequently associated with second-trimester miscarriages and which are also linked with uterine anomalies. Cervical weakness is a frequently documented cause of second-trimester miscarriage, although the real prevalence is uncertain. A septate uterus has been associated with increased firsttrimester miscarriage because of impaired implantation $[35,36]$. A uterine septum is usually composed of fibromuscular tissue which is poorly vascularized, and this poor vascularization may compromise the developing fetus, thus affecting the decidual or placental development and hence leading to miscarriage.

There is still some controversy amongst researchers and clinicians in their efforts to distinguish between septate and bicornuate uteri through diagnostic tests, and there is no significant difference in the outcome of pregnancy before and after correctional surgery for these malformations: a recent report has stated that $35.1-65.9 \%$ of patients had live births after correctional surgery compared with $33.3-59.5 \%$ of live births without correctional surgery [37]. This equivocal and rather inconclusive information poses great difficulty to the treating physician and is an area of challenge in decision-making, investigation and treatment of patients with RSM who need to be screened for these suspected anatomical disorders.

\section{Antiphospholipid Syndrome}

Antiphospholipid antibodies (APLs) are acquired antibodies (immunoglobulins IgG, IgM and/or IgA) which react against negatively charged phospholipids in the cells and which were originally linked with thrombosis and infarction in the placenta, thus causing some obstetric morbidities [38]. APLs have been reported in 15\% of patients with RSM [39] and in $2 \%$ of women with a low-risk obstet-
Diejomaoh 
Table 3. Clinical and laboratory criteria established for the research of definite APS

\section{Clinical criteria}

1. Vascular thrombosis One or more clinical episodes of an arterial, venous or small vessel thrombosis, confirmed by imaging or Doppler studies or histopathology, without significant evidence of inflammation in the vessel wall

2. Obstetric morbidity

a. One (or more) unexplained demise of a morphologically normal fetus at or beyond 10 weeks of gestation, or

b. One or more premature births of a morphologically normal neonate at or before 34 weeks of gestation, due to severe preeclampsia or severe placental insufficiency, or

c. At least 3 unexplained consecutive miscarriages $<10$ weeks of gestation; known factors associated with recurrent miscarriage including parental genetic, anatomical and endocrinological factors should be ruled out

Laboratory criteria

1. ACL IgG and/or IgM in blood, present in medium or high titres ( $>40$ GPL or MPL or $>99$ th percentile) on 2 or more occasions at least 12 weeks apart, measured by standardized ELISA

2. Anti- $\beta_{2}$-glycoprotein I antibody of the IgG and/or IgM isotype in blood ( $>99$ th percentile) on 2 or more occasions at least 12 weeks apart, measured by ELISA

3. Lupus anticoagulant present in plasma on 2 or more occasions at least 12 weeks apart, detected according to the Guidelines of the International Society on Thrombosis and Haemostasis, which include the following steps

a. Prolonged phospholipid-dependent coagulation using a screening test such as the activated partial thromboplastin time, kaolin clotting time, dilute Russell's viper venom time, dilute prothrombin time

b. Failure to correct the prolonged coagulation time on the screening tests by mixing with normal plasma

c. Shortening or correction of the prolonged coagulation time on the screening tests by the addition of excess phospholipids or platelets

d. Exclusion of other coagulopathies (e.g., factor VIII inhibitor) or heparin

At least 1 clinical and 1 laboratory criterion must be present for definite APS. From Miyakis et al. [110].

ric history [40, 41]. Antiphospholipid syndrome (APS), regarded as an autoimmune condition, is characterized by the production of APLs which are anticardiolipin (ACL) antibodies and lupus anticoagulants and by some clinical features of adverse pregnancy outcome [42]. The incidence of APS reported in a large meta-analysis on RSM was 15$20 \%$, which is much higher than the $5 \%$ incidence in non-
Table 4. Mechanisms of APL-induced pregnancy morbidity

The possible mechanisms of action can be summarized as follows:

1. Inhibition of trophoblastic invasiveness, function and differentiation $\rightarrow$ early pregnancy loss rather than intervillous thrombosis

2. Decreased prostacyclin production by endothelial cells; platelets are therefore released to act in step 3

3. Increased thromboxane production by platelets; the outcome is increased platelet aggregation

4. Decreased protein $\mathrm{C}$ activation

5. Disruption of placental protein, annexin V

6. Activation of the complement pathways at the maternal fetal interface $\rightarrow$ local inflammatory response

7. Thrombosis of the uteroplacental vasculature $\rightarrow$ infarction of placenta $\rightarrow$ placental insufficiency (later in pregnancy)

8. Higher risk of thrombosis with lupus anticoagulant than with ACL antibodies

pregnant women without a history of obstetric complications $[43,44]$. The pathway for the development of APLs has not been well established, although genetic factors and infection may play a role and some family studies have suggested a genetic predisposition to APS [42].

The diagnosis of APS is based on both clinical manifestations of adverse pregnancy outcome and laboratory detection of abnormal antibodies. The clinical criteria include a history of RSM, fetal loss and venous and/or arterial thrombosis, and the laboratory criteria include the detection of moderately elevated or high APLs and/or thrombocytopenia. Antibody titre elevation should be detected on at least 2 occasions, 3 months apart [5, 14, 42]. The comprehensive criteria for definite APS are documented in table 3 .

It is pertinent to note that APS may be defined as 'primary' in patients without clinical or laboratory evidence of any underlying disease or condition (apart from those in APS) and as 'secondary' when it is associated with other diseases or conditions such as systemic lupus erythematosus, rheumatoid arthritis, diabetes mellitus, malignancies (cervix/ovary), drug intake (oral contraceptives), and infectious conditions (syphilis, HIV).

The mechanisms through which APLs cause pregnancy-induced morbidity are itemized in table 4 . Inherited thrombophilias have been associated with increased risks of systemic thrombotic disorders such as deep vein thrombosis and pulmonary embolism $[45,46]$. They have also been identified as aetiological factors in RSM and late 
fetal pregnancy loss and complications, through the possible mechanism of increased thrombosis of the uteroplacental vessels leading to placental infarctions [1-3, 5, 4648]. The inherited thrombophilias associated with RSM include factor V Leiden (deficiency/carrier status), prothrombin G20210A gene mutation, deficiencies in antithrombin III, protein $\mathrm{C}$ and protein $\mathrm{S}$, and hyperhomocysteinaemia which may be partly caused by polymorphism of C677 in the methylenetetrahydrofolate reductase (MTHFR) gene. The association of inherited thrombophilias with the aetiology of RSM remains controversial with inconsistent results from previous studies [4951], and the weak evidence in support of their role in RSM calls for further comprehensive studies [1, 5, 46, 48]. A meta-analysis of 16 case-control studies [52] reported that the risk of RSM was doubled in carriers of factor V Leiden or prothrombin gene mutation compared with non-carriers, and some prospective studies have reported an increased risk of miscarriage in untreated pregnancies in carriers of factor $\mathrm{V}$ Leiden mutation compared with non-carriers presenting with RSM $[53,54]$. However, another prospective study [55] reported no adverse effects in the live birth rate in women with hereditary thrombophilias presenting with RSM. The role of inherited thrombophilias in the aetiology of RSM remains controversial and clearly poses a great challenge, creating uncertainty in many physicians treating patients with RSM.

\section{Endocrine Factors}

Poorly controlled or untreated endocrine disorders such as diabetes mellitus and thyroid dysfunction have been associated with spontaneous miscarriage [3-5]. However, well-controlled diabetes mellitus and treated thyroid dysfunction do not increase the risk of RSM $[56,57]$. The prevalence of diabetes mellitus and thyroid dysfunction in the general population is comparable with the rate in patients with RSM $[58,59]$. The role of the presence of antithyroid antibodies in women with RSM remains controversial. A recent study [60] demonstrated that there was no role for antithyroid antibodies in the aetiology of RSM in euthyroid patients, and this is in agreement with the findings of a previous study [61]. Hyperprolactinaemia, which has been linked to thyroid disorders, has also been associated with the aetiology of RSM, although the mechanism is not clearly established.

Polycystic ovary syndrome (PCOS) has been associated with an increased risk of miscarriage and RSM, although the exact mechanism for this association remains uncertain $[5,47]$ and the incidence reported is quite var- ied: PCOS has been associated with RSM in $56 \%$ of the population $[62,63]$, whereas a rate of $21.1-40 \%$ was reported from Kuwait $[64,65]$ and a lower rate of $8.3-10 \%$ in the study of Cocksedge et al. [66]. Hyperinsulinaemia, increased insulin resistance and hyperandrogenaemia, which have all been reported in PCOS, have been linked with an increased risk of miscarriage and RSM. Although an increased prevalence of insulin resistance was reported in non-pregnant women with RSM compared with matched fertile controls in Craig et al. [67], this was not confirmed in another study [68]. The recent study of Wang et al. [69] showed that there was an increased risk of insulin resistance in the early stages of pregnancy in women with a history of RSM compared with those without such a history.

\section{Other Immune-Related Factors and the Role of \\ Natural Killer Cells}

The role of alloimmune factors in the aetiology of RSM remains controversial, and the hypothesis of human leucocyte antigen (HLA) incompatibility between couples presenting with RSM and the role of maternal blocking antibodies in RSM have not been clearly substantiated.

In spite of extensive investigations in RSM patients, the treating physician still faces huge challenges in confirming the aetiological factors in all patients with RSM. In $50-60 \%$ of patients, the aetiology of RSM remains elusive, unidentified or unexplained $[65,70]$. An immunological reason has been proposed as the underlying basis of these unexplained RSM [71] although the exact mechanism has not been elucidated. Undiagnosed or unrecognized chromosome anomalies may also play a significant contributory aetiological role. Surely, the inability of the treating physician to confirm the aetiology in $>50 \%$ of the patients investigated for RSM is not welcomed by the patients and it remains a great challenge and a source of concern for the medical expert.

Intensive research in the last 17 years has focused on cellular constituents/processes to explain the immunological basis for RSM [71], and natural killer (NK) cells have been extensively evaluated as a probable contributing factor. NK cells, constituent parts of the innate immune system, are the predominant leucocyte cell population present in the endometrium during the period of implantation and early pregnancy [71]. NK cells are also found in peripheral blood. Whereas uterine NK cells (uNK) and peripheral blood NK cells (pNK) express the same surface antigen CD56, uNK and pNK cells are functionally and phenotypically different [72]. The intensity of CD56 expression can be used to divide NK
Diejomaoh 
Table 5. Investigations recommended for RSM by ESHRE

Basic investigations

Obstetric and family history, age, BMI, organic solvent, alcohol, mercury, lead, caffeine, hyperthermia, smoking Full blood count (blood sugar level and thyroid function tests) APLs (LAC, ACL)

Parental karyotyping (after 2 miscarriages)

Pelvic US and/or HSG and hysteroscopy and laparoscopy

in the case of inconclusive findings

Research investigations within the context of a trial

Fetoplacental karyotype studies

Testing for uterine and/or peripheral blood NK cells

Mannan-binding lectin level

Luteal phase, endometrial biopsy

Homocysteine/folic acid level

Thrombophilia screening

From Jauniaux et al. [3]. LAC = Lupus anticoagulant; US = ultrasound; HSG = hysterosalpingogram.

cells into two populations [73]. A very high population of pNK cells (90\%) are CD56 $6^{\mathrm{dim}}$ and CD16 ${ }^{+}$, and the remaining $10 \%$ of pNK cells are CD56 $6^{\text {bright }}$, with low levels of or absent $\mathrm{CD} 16^{+}[73]$. It has been suggested that the uNK cells are derived from this smaller population of pNK cells. In 90\%, pNK cells are CD56 $6^{\mathrm{dim}}$ and CD16 ${ }^{+}$, whereas $80 \%$ of uNK cells are CD56 $6^{\text {bright }}$ and CD16 ${ }^{+}$. uNK cells have limited cytotoxic activity and are the major source of NK cell immune regulatory cytokines [7376] which may play a role in trophoblastic invasion and angiogenesis.

As previously stated, NK cells are the predominant leucocyte in the endometrium during the period of implantation and early pregnancy [71]. In normal pregnancy, previous studies have demonstrated a reduction in the number of pNK cells, and this has enhanced the progress of normal pregnancy [77, 78]. Other studies have reported that an increased NK cell population has been associated with implantation failures after embryo transfers or RSM [79-82].

Various studies have established background information on a Th1/Th2 balance for the successful progression of pregnancy. Enhanced Th1 activity on the trophoblast cells is associated with RSM, whereas enhanced Th2 is associated with progression of pregnancy. Successful pregnancy is considered as a Th1/Th2 balance with positive Th2 and a predominantly Th2 lymphocyte response, with the role of IL-12, IL-15, IL-18, and other soluble factors dependent on NK cells [83-86]. Increased pNK cells have been linked to increased Th1 activity and migration of cytotoxic cells into the uterus, with progression to RSM. On the other hand, Th2 immunity to trophoblast cells is mainly suppressed during pregnancy, thus allowing the pregnancy to continue, whereas the failure of such suppression leads to increased trophoblastic cytotoxic activity in the uterus resulting in a loss of pregnancy and RSM [71]. Decreased pNK cells have been linked to enhanced Th2 activity with diminished cytotoxic activity in the uterus and continuation of pregnancy. This finding is not universally accepted. The mechanisms associating NK cells (pNK and uNK cells) with unexplained RSM have not been fully established $[71,74]$.

\section{The Role of Infections}

The role of infections in the aetiology of RSM remains controversial, certainly unresolved, and is a dilemma for the treating physician [5]. Severe maternal viraemia and bacterial and parasitic infections which lead to high levels of pyrexia can cause sporadic miscarriages and preterm delivery. However, persistent prolonged maternal infections due to these infecting agents which could be linked to the aetiology of RSM should leave significant maternal effects, and these have not been documented in patients with RSM. Infections due to rubella, herpes, cytomegalovirus, and toxoplasmosis (infections that have usually been associated with the aetiology of RSM) do not meet these specifications, and efforts to screen for them empirically using the tests classified as TORCH (toxoplasmosis, rubella, cytomegalovirus, herpes) should not be continued $[87,88]$. Bacterial vaginosis has been associated with the aetiology of spontaneous miscarriages, preterm delivery and RSM [89-92] although the outcome of the Cochrane systematic review [93] of the treatment of bacterial vaginosis has not resolved the full benefits of screening for bacterial vaginosis in the prevention of preterm delivery and RSM by deduction.

In spite of extensive studies and reviews, the aetiology of RSM remains unexplained, idiopathic or unknown in about 50\% (range 35-65) of the cases of RSM encountered by treating physicians, leaving them challenged and in a quandary, since a majority of patients do not readily accept the information that there is no explanation/cause for their RSM. Parental karyotype abnormalities, APS and uterine anatomic abnormality are universally accepted as the main causes of RSM in about $50 \%$ of all the patients presenting with this clinical entity [1-6]. 
Table 6. RSM investigations at the Maternity Hospital, Kuwait

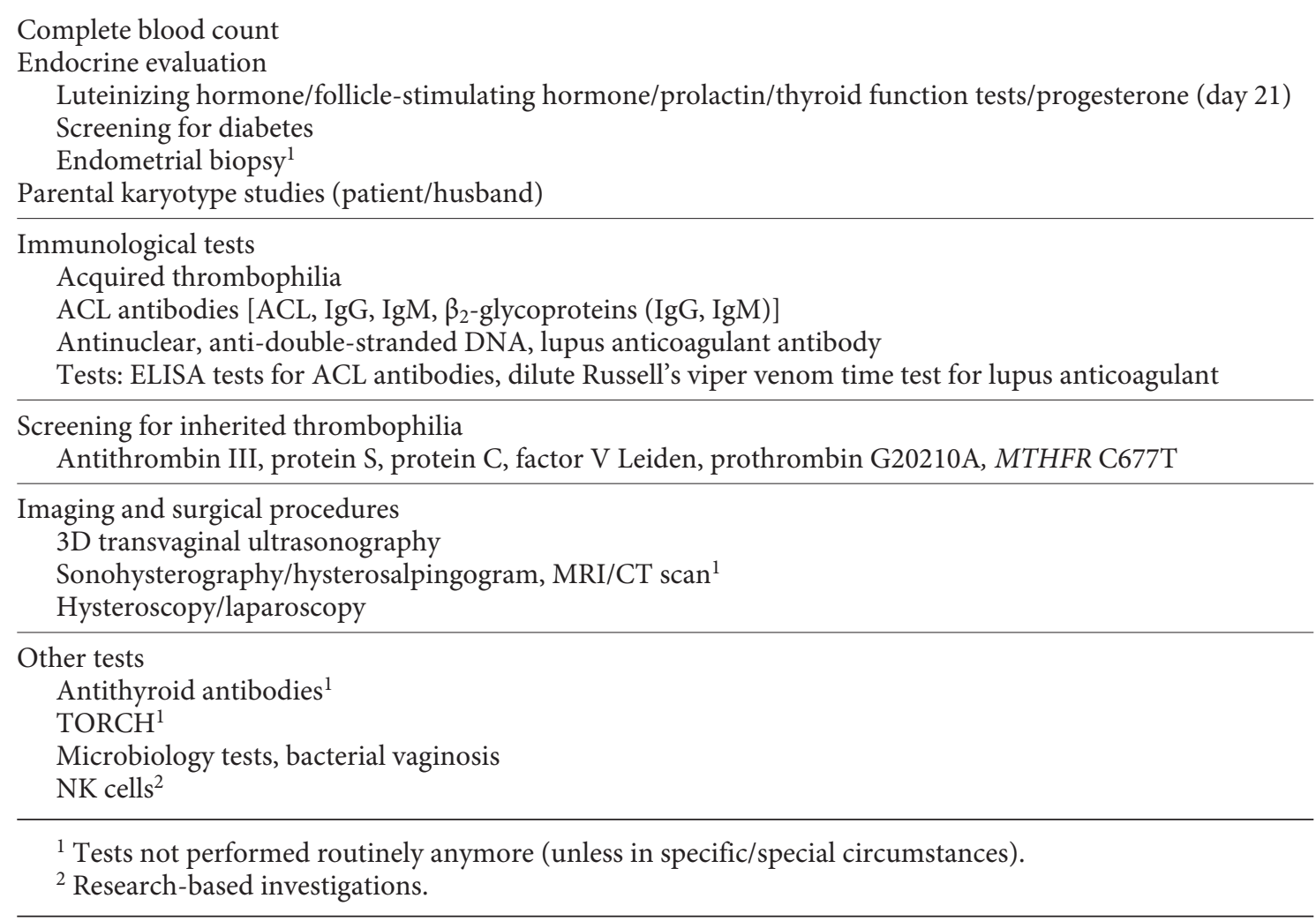

\section{RSM Investigations}

It is the aim of the various tests and ancillary investigations to establish the cause of RSM based on understanding and on the available facilities. The investigation and treatment of all patients should preferably be carried out by specially designated RSM clinics run by trained personnel. The investigations recommended by the European Society of Human Reproduction and Embryology (ESHRE) for all patients presenting with RSM are listed in table 5 . The RSM clinics should use specially prepared written documents which include a comprehensive history of all social biodata and all the previous miscarriages as well as of past obstetric, gynaecological, medical and surgical events, and a detailed menstrual history. These clinics should also have a comprehensive list of investigations using suitable available documents and facilities. The RSM investigations at the Maternity Hospital, Kuwait, are laid out in table 6; they are similar to those recommended by ESHRE.

\section{Initial Investigations}

Basic endocrine investigations include thyroid function tests, screening for diabetes mellitus, serum prolactin estimation, and basic pituitary function tests (luteinizing hormone and follicle-stimulating hormone). These tests may be repeated if results are equivocal.

Parental peripheral blood karyotyping should ideally be performed, but in view of the huge costs involved, many experts recommend selective parental karyotyping, and this approach to screening is implemented at the Maternity Hospital, Kuwait, using a combination of discriminatory factors such as the age of the couple, a high number of previous miscarriages $(\geq 4-5)$, and a family history of genetic/chromosomal disorders. Although cytogenic analysis of the products of conception is recommended $[3,4,5,14]$, it is not routinely performed at the Maternity Hospital, Kuwait, and the cost-benefit analysis of such procedures requires prospective studies of large populations [3]. When balanced chromosome translocation or inversion is confirmed in a parent after karyotype studies, preimplantation genetic diagnosis (PGD) with in
Diejomaoh 


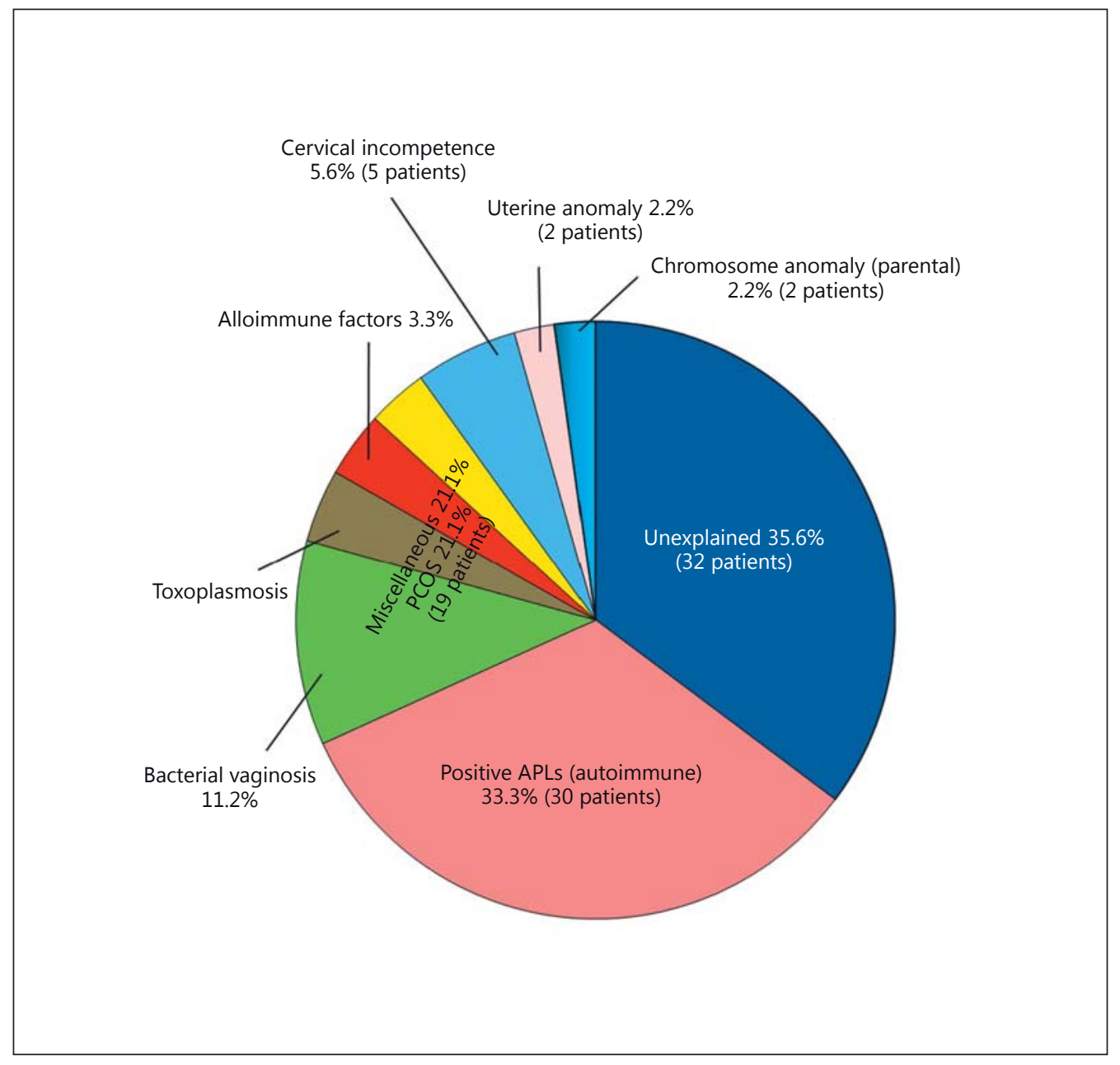

Fig. 1. Aetiology of RSM in Kuwait. From Diejomaoh et al. [64].

vitro fertilization (IVF) is performed with the selection and transfer of a chromosomally normal embryo [31,32]. The practice of preimplantation genetic screening (PGS) with IVF is recommended for parents who are chromosomally normal in an effort to detect aneuploid embryos $[31,32]$, although this method of testing (PGS with IVF) is still controversial. Whereas PGS was previously performed using fluorescence in situ hybridization which evaluated 5 and 14 chromosome pairs, this process has been enhanced by a combination with new microarray technology using single nucleotide polymorphism (SNP) or comparative genomic hybridization which evaluates all 23 chromosome pairs, with SNP arrays giving superior results for pregnancy outcome $[31,32]$.

\section{Antiphospholipid Syndrome}

APS is the most frequently diagnosed immunological cause of RSM [5]. The diagnosis should be based on the mandatory adherence to the rule of two positive tests at least 12 weeks apart for either lupus anticoagulant or ACL antibodies of the IgG and/or IgM class at a medium or high titre $[1,3,5,6,14,38,42]$. In some patients, all three antibody tests may be positive. A failure to adhere to this strict guideline in diagnosis by some colleagues contributed to the high incidence of 33\% reported for APS in our earlier report on RSM (fig. 1) [64]; this rate was reduced in later studies to $15-20 \%[15,65]$. Practitioners in this field should avoid short cuts in the care of their patients so that they do not fall prey to such diagnostic pitfalls. Lupus anticoagulant has been detected in Kuwait and in other countries $[3,5,64,65]$ by the dilute Russell viper 
venom time test and other coagulation tests, and ACL (IgG/IgM) are determined by ELISA. The $\beta_{2}$-glycoproteins $\left(\beta_{2} \operatorname{IgG} / \beta_{2} \operatorname{IgM}\right)$ for the main ACL antibodies are estimated in all patients being investigated for RSM in Kuwait $[64,65]$; these investigations are recommended by professional organizations. There is considerable inter-laboratory variation [94], and standardized methods should be used and appropriate normal levels of antibody titre should be set for each centre so that abnormal/elevated results can be easily identified. In Kuwait, the antibody tests for APS are performed in a centralized laboratory and the levels of positivity are established [64, 65]. Temporary fluctuations in antibody titres may be reported in individual patients, and transient positive titres especially for ACL IgM may be recorded secondary to infections; therefore, in some patients, several tests may be required before a definitive diagnosis is made.

The screening for inherited thrombophilias includes screening for antithrombin III, factor V Leiden, prothrombin G20210A, protein C and protein $S$ as well as for MTHFR C-677T polymorphisms, and these tests should be done before pregnancy because of the physiological changes in some of these thrombophilias during pregnancy (protein S and C). Robertson et al. [48] have called for larger epidemiological studies to justify the inclusion of routine screening for inherited thrombophilias in RSM clinics because of some conflicting reports $[45,95]$ on the impact of inherited thrombophilia on RSM and other adverse pregnancy outcomes.

\section{Imaging and Related Operative Procedures}

Transvaginal ultrasonography is essential in the diagnosis of uterine anatomical disorders, in establishing the endocrine function of the ovaries and uterus and in diagnosing PCOS. Pelvic ultrasonography and/or hysterosalpingography (sonohysterography in some expert hands) may be useful as initial screening tests. However, a combination of 3D pelvic ultrasound (3D or higher), hysteroscopy and laparoscopy are required to confirm the diagnosis of uterine anomalies and ovarian disorders in specific/special circumstances.

\section{Miscellaneous Tests}

The controversy over the role of infections and antithyroid antibodies in RSM has called into question the need for screening for these conditions. Routine estimation of anti-thyroid antibodies, the performance of $\mathrm{TORCH}$ and screening for bacterial vaginosis are not supported by existing guidelines for the investigation and management of RSM $[3,5,14]$. However, some cen-
Table 7. General outline of treatment of RSM

\section{Background}

- The aetiology of RSM is multifactorial

- Appropriate treatment continues to be a challenge

- Tender loving care is essential

- APS is the most treatable cause of RSM, but there is a scarcity of large placebo-controlled trials in women with RSM

- There is no robust evidence for LDA or LDA and heparin therapy leading to an improved pregnancy outcome in inherited thrombophilia

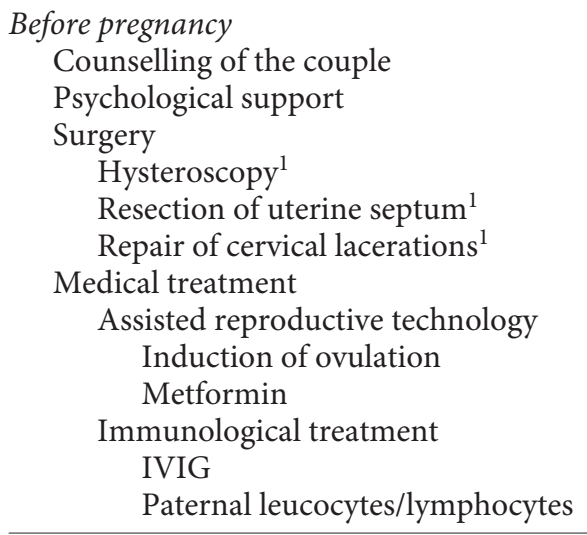

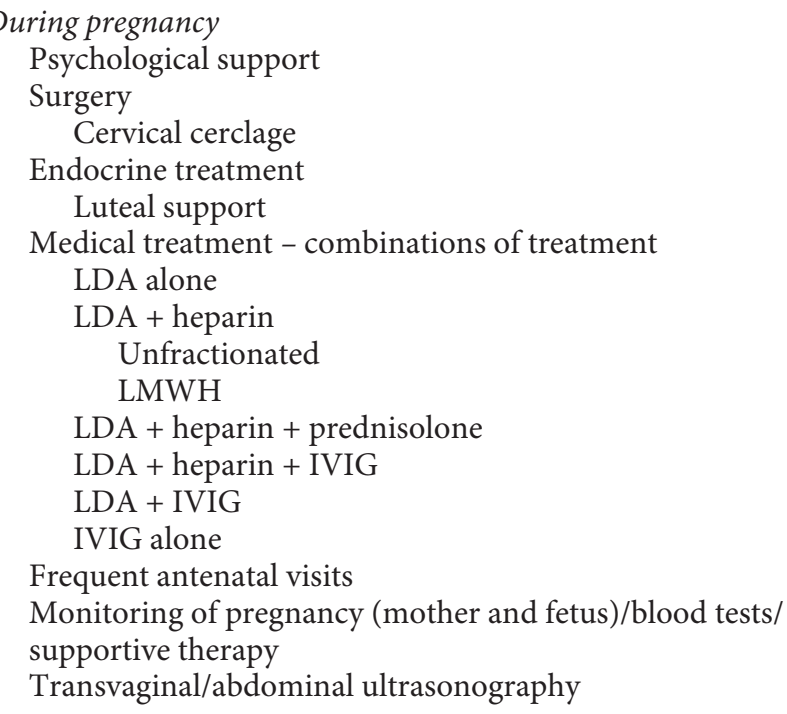

${ }^{1}$ These procedures should be performed before another planned pregnancy.

tres still routinely perform these tests and certainly add to the dilemma faced by physicians aiming at delivering the proper care for patients with RSM. These tests are not performed routinely at the Maternity Hospital, Kuwait.
Diejomaoh 
Other investigations such as HLA typing, NK cells (uNK/pNK cells), cytokines Th17 and Th1/Th2 ratios, embryotoxicity assay, sperm, DNA fragmentation tests [47], and angiogenic mediators should be seen as research tools and should only be offered in research-oriented RSM clinics. A recent review [86] failed to identify any significant association between unexplained RSM and cytokine gene polymorphism, and thus, the authors do not recommend the inclusion of cytokine assays and angiogenic mediators in routine RSM investigation. Beaman et al. [96] believe that increased testing for patients with RSM is necessary as it may lead to the detection of more causes of RSM, and thus recommend increased genetic testing, testing for HLA-C ligands, NK cell counts, NK cytotoxicity assays, and Th1/Th2 cytokine ratios. The uncertainty in regard to the real benefits of diagnostic testing and RSM investigations rages on.

\section{Treatment of RSM}

The general guidelines for the treatment of RSM at the Maternity Hospital, Kuwait, are outlined in table 7. The investigation and treatment of RSM should be undertaken in specially designated clinics/centres which should be run by trained or qualified personnel equipped with readily available facilities (on site or nearby) for all ancillary investigations. If care is provided by ad hoc partially trained personnel, appropriate guidelines may not be followed and the outcome/results reported will not be subject to proper interpretation and application. New treatment options should only be implemented in centres which are engaged in research activities to facilitate the application of these research findings in future and in more widespread treatment. Further, there is the need for larger well-planned double-blinded randomized controlled trials or standardized research protocols to be applied in the utilization of new or even well-established investigations and treatment of RSM to effectively resolve many of the problems which remain a source of quagmire for most treating physicians $[3-6,14]$.

\section{Treatment before Pregnancy}

As outlined in table 7, when treatment starts before pregnancy, the couple should be fully counselled about the approach to investigations; they should be fully informed about the outcome of the investigations, the treatment plan to be followed, and the outcome of such treatment. Patients presenting with RSM are usually quite anxious and full of uncertainty about the outcome of the next pregnancy. Strong psychological support should be provided and sustained all through the period of consultation and tender loving care should always be offered to the patients.

When abnormal parental karyotypes are detected during the screening period, the couple should be referred to a clinical geneticist, where available, for detailed counselling about the outcome of future pregnancies. The couple could be encouraged to proceed with another pregnancy with natural conception and take a chance with the next pregnancy [5], a line of management followed frequently in our clinic in Kuwait. In some other centres, advice may include prenatal diagnosis (chorionic villus sampling/ amniocentesis), gamete donation and even adoption, options that are not offered at the Maternity Hospital, Kuwait. The couple should be informed that they have a $5-10 \%$ chance of recurrence of another natural untreated pregnancy with a balanced translocation [97] and quite a favourable rate of $50-70 \%$ of a healthy live birth in future untreated natural pregnancies $[28,29,98]$. PGD with IVF has been recommended as treatment for translocation carriers [4, 5, 31, 32, 47, 97, 99-102], but the patients should be aware of the lower pregnancy rate with IVF. PGS with IVF combined with the microarray technology preferably using SNPs or comparative genomic hybridization may also be offered to patients with no chromosome anomalies. PGD with IVF/PGS with IVF and SNP are not frequently offered to our patients in Kuwait, leaving the treating physicians with more challenges; such services may be more freely offered in the future as there are developments that will enable such services to come on-stream.

The correction of detected anatomical disorders (congenital and acquired) including hysteroscopic resection of congenital uterine septum, preferably using cold scissors rather than cautery or bipolar cutting devices, resection of submucous fibroids, and treatment of intrauterine adhesions presenting as Asherman syndrome should be undertaken before another pregnancy is embarked upon. Patients who have multiple uterine fibroids with a large uterine size exceeding 14 weeks' gestational size should be encouraged to secure appropriate treatment (including myomectomy) before embarking on another pregnancy. However, it should be noted that the exact role of a resection of the uterine septum is still unresolved [103] since there are no published controlled randomized trials of the benefits of surgical correction of uterine abnormalities on pregnancy outcome $[4,5,47]$. Uncontrolled studies have indicated a positive effect on pregnancy outcome $[4,5,32$, 37, 47]. In Kuwait, we have identified congenital uterine 
septum as an aetiological factor in RSM (fig. 1) [64] and we have recorded successful pregnancies in some patients who had uterine septum resection.

Surgical correction of traumatic cervical lacerations should be undertaken before further pregnancies are planned $[5,63,64,97]$. Cervical cerclage in pregnancy will be discussed later when dealing with the management of RSM in pregnancy. Transabdominal cerclage has been offered as an alternative treatment for patients presenting with second-trimester miscarriage or early preterm labour who have had unsuccessful transvaginal cerclage because of a short or scarred cervix [104-106]. A systematic review comparing abdominal with vaginal cerclage has indicated a lower risk of delivery before 24 weeks' gestation [107] although the timing of performing transabdominal cerclage before or during pregnancy remains unresolved [108].

Endocrine disorders including thyroid dysfunction and diabetes mellitus should be well controlled before another pregnancy is planned. Patients presenting with PCOS should be appropriately managed with medical and surgical methods to achieve regular ovulation, and assisted reproductive technology may be indicated in some of these patients with PCOS.

\section{Treatment during Pregnancy}

Psychological support and tender loving care should be continued all through the pregnancy. I have encouraged more frequent antenatal visits (usually 2 weekly appointments) to the clinic for all patients with RSM and this has been very well accepted by the patients as they feel more reassured and supported. The real benefits of these frequent visits are being evaluated by an ongoing prospective study. The endocrine treatment for thyroid dysfunction and diabetes mellitus is continued to ensure that these endocrine disorders are well controlled.

\section{Antiphospholipid Syndrome}

APS, the most frequently diagnosed immunological cause of RSM and the only proven thrombophilia associated with an adverse pregnancy outcome, has also been identified as the most treatable cause of RSM [1, 109]. The treatment recommended for APS is a combination of low-dose aspirin (LDA) plus heparin, and this treatment modality for RSM will help prevent further miscarriages [1-7, 14, 42, 46, 47, 110-112]. However, this treatment has attracted some controversy [1] and has been the subject of multiple publications $[1,5,42]$. A Cochrane review [113] including 13 trials (849 women), a meta-analysis of randomized controlled trials, which reviewed the outcome of various treatments including aspirin, steroids, intravenous globulin, and heparin, given to women with RSM and APS to improve pregnancy outcome, reported that only treatment with a combination of aspirin and unfractionated heparin reduced the rate of miscarriage by $54 \%$. Another metaanalysis of 334 patients [114] with RSM and APS reported a live birth rate of $74 \%$ in those patients treated with heparin and aspirin compared with a live birth rate of $56 \%$ in patients treated with aspirin alone [114]; this meta-analysis also confirmed the superiority of heparin combined with aspirin compared with aspirin alone in the treatment of RSM associated with APS. There were limitations in both meta-analyses [113, 114]; these arise from the design and quality of the studies and the small number of patients in the trials included in the second meta-analysis [114]. The live birth rate of $82 \%$ reported in a Kuwait study [115] in which patients with RSM and APS were treated with LDA, unfractionated heparin or low-molecular-weight heparin (LMWH) is comparable to the above result of 74 and $79 \%$ reported in the AOCG Practice Bulletin [116] where LMWH was combined with LDA. Two smaller studies $[117,118]$ have not reported any significant differences in pregnancy outcome with the combination therapy using unfractionated heparin and LDA and LMWH and LDA in patients with RSM associated with APS. Although some other studies have raised doubts about the benefits and value of heparin $[119,120]$, there is overwhelming evidence supporting the use of heparin (unfractionated heparin) and LMWH combined with LDA in the management of patients presenting with RSM associated with APS [1-7, $14,42,46,47,110-112,116,121]$. Treatment with heparin and LDA should be commenced as soon as a pregnancy test is positive and continued all through pregnancy and into the puerperium with specific breaks. LDA should be stopped at 35 weeks' gestation because of some adverse neonatal effects of LDA, and heparin should not be administered during labour and operative obstetric operations because of the risk of haemorrhage. Corticosteroids administered to women during pregnancy presenting with RSM associated with APS do not improve the live birth rate compared with heparin and LDA [113], and such therapy should not be encouraged, especially as corticosteroids are associated with significant fetal and maternal morbidity. If the treating physician has a choice in the type of heparin used, then it should be stated that LMWH has advantages over unfractionated heparin as the former drug is usually administered daily and is associated with less heparin-in-
Diejomaoh 
duced thrombocytopenia and a lesser risk of heparininduced osteoporosis.

Physicians face great challenges and are clearly in a quagmire when it comes to the treatment of women presenting with RSM associated with inherited thrombophilia because there is no strong evidence to support the treatment of these patients with aspirin and/or heparin $[1,5,47]$. Women with inherited thrombophilia have an increased risk of venous thromboembolism, suggesting that aspirin and/or heparin should be useful in the treatment of these patients; it has been suggested that they may improve the live birth rate in women who have secondtrimester miscarriages associated with inherited thrombophilia. Although some studies have indicated that heparin may improve live birth rates in women with inherited thrombophilia [122-124], a more recent study by Viser et al. [125] has stated that there was no significant difference in the live birth rate in women with RSM and inherited thrombophilia who have been treated with a combination of aspirin and LMWH or aspirin alone. In Kuwait, we have observed positive results in the live birth rate of our patients who presented with protein $S$ and protein C deficiency and RSM. In a specific case of protein S deficiency, the patient had 3 successful live births and the puerperium was complicated by an episode of cerebrovascular accident due to cerebral vein thrombosis after stoppage of LMWH. She made a complete recovery and had a successful 4th live birth during which LMWH and LDA were continued all through pregnancy and the puerperium, and further anticoagulant therapy was continued under the care of a haematologist after discharge from the postnatal clinic.

\section{Treatment of RSM Patients with Cervical Disorders}

Because of conflicting evidence, the management of women presenting with RSM, usually late in the first trimester, and with second-trimester miscarriages is really difficult for the treating physician who needs to decide on the definitive treatment for such patients $[5,126]$. A meta-analysis [127] of 4 randomized controlled trials reported that prophylactic cerclage did not reduce the risk of miscarriage or preterm delivery in women at risk of such disorders because of cervical weakness. Another meta-analysis [128] on women from 4 randomized controlled trials with a short cervix $(<25 \mathrm{~mm}$ diagnosed by transvaginal ultrasound examinations) and a history of previous second-trimester miscarriage confirmed that cervical cerclage may reduce second-trimester miscarriages and the incidence of preterm delivery. It has been documented that cervical cerclage may be associated

Recurrent Spontaneous Miscarriage Is Still Challenging and Controversial with some minor maternal morbidity $[5,126,128]$. It has been the practice in Kuwait to perform prophylactic cerclage in women who present with a history of recurrent second-trimester miscarriages, a history of a typical single second-trimester miscarriage, or with ultrasound-indicated cervical weakness where a cervical length of 25 $\mathrm{mm}$ or less has been detected by transvaginal ultrasound, adhering to the principles contained in a recent guideline [126]. In some women with a less specific history, serial cervical ultrasonographic surveillance is carried out in the index pregnancy and prophylactic cerclage performed when indicated by a cervical length of $<25 \mathrm{~mm}$. The treating physicians at the Maternity Hospital, $\mathrm{Ku}-$ wait, consider it much too dangerous to continue ultrasound surveillance up to a cervical length of $15 \mathrm{~mm}$, as recommended elsewhere $[11,14,111]$, before performing a cervical cerclage.

\section{Role of Progesterone}

In a landmark study, Csapo et al. [129] laid the foundation for the fact that progesterone was essential in the maintenance of early pregnancy. Other authors [130, 131] have indicated that progesterone therapy was not essential in preventing miscarriages. In spite of the fact that progesterone has been identified as being essential for the implantation and maintenance of pregnancy [36], great controversy still exists about the role of progesterone supplementation in supporting early pregnancy and in the prevention and/or reduction of first-trimester miscarriages/recurrent early spontaneous first-trimester miscarriages. The use of progesterone supplementation is an area of great challenge to the treating physician (especially in Kuwait), having to sort out those patients with RSM who may benefit from progesterone therapy versus those in whom the treatment is clearly uncalled for and could pass as a form of medical malpractice [35, 32, personal experience in Kuwait]. Progesterone has an immunomodulatory action in inducing a pregnancyprotective shift from pro-inflammatory cytotoxic Th1 cytokines to a more favourable anti-inflammatory and less cytotoxic Th2 cytokine response that encourages the progression of pregnancy $[71,132]$; this shift also encourages a more favourable NK cell population with a reduction/decrease in pNK cells which is linked to diminished cytotoxic activity and a continuation of pregnancy. Although a meta-analysis by Haas and Ramsey [133] did not confirm any positive role for progesterone in sporadic miscarriage, a further subgroup analysis of women with RSM in that study showed that progesterone therapy was positively associated with a significant 
reduction in the miscarriage rate in those with RSM compared with placebo or no treatment. Duphaston (dydrogesterone, a synthetic progesterone), administered as tablets, was not only significantly associated with a prolongation of pregnancy in patients with threatened miscarriage but was also significantly associated with successful viable pregnancies and a reduction in miscarriages in patients with RSM who were treated with duphaston $[134,135]$. Duphaston therapy has been associated with a shift of Th1 to Th2 cytokines, and thus, contributes to the promotion/progression of pregnancies. In the light of the above presumed benefits of the use of progesterone in RSM, duphaston tablets and other natural vaginal progesterone pessaries (Cyclogest) are administered to deserving patients in Kuwait presenting with RSM.

\section{The Role of Other Forms of Therapy Using Immunologically Related Therapies}

The treating physician faces a lot of pressure in deciding on whether to offer some other forms of controversial therapy to patients presenting with idiopathic or unexplained RSM. Paternal cell immunization/lymphocyte therapy/third-party donor leucocytes and intravenous immunoglobulin which have been independently administered to patients with previous unexplained RSM have not been associated with sustained improved live birth rates. A Cochrane systematic review [136] has demonstrated that immunotherapy in the form of paternal cell immunization, third-party donor leucocytes and intravenous immunoglobulin in women with unexplained RSM were not associated with any significant beneficial effect in RSM compared with placebo. A recent randomized, multi-centred, double-blinded, placebo-controlled trial and meta-analysis [137] did not report any treatment benefit for intravenous immunoglobulin (IVIG) in patients with idiopathic unexplained RSM. Further, another systematic review [138] reported no beneficial effect of IVIG in the treatment of unexplained RSM. However, in a previous study by Christiansen et al. [139], the authors had demonstrated an enhanced pregnancy outcome for patients with secondary RSM who were treated with IVIG (58\% successful pregnancy rate in treated patients vs. $24 \%$ pregnancy in placebo-treated patients; $\mathrm{p}<0.02$ ), and a meta-analysis of 8 randomized controlled studies [140] also confirmed a positive benefit for the use of IVIG in idiopathic RSM. Intravenous immunoglobulin has been reported to have a positive effect on the downward regulation of elevated NK cells in patients with RSM, thus contributing to a successful pregnancy outcome in such patients [141]. A recent review [141] has concluded that IVIG was effective in suppressing NK cell cytotoxicity and in enhancing live births in women with RSM and elevated NK cell activity. There are other controversial aspects related to the use of IVIG in idiopathic RSM including standardized dosage regimes, frequency of administration of IVIG, duration of therapy, high costs, and the real possibility of adverse effects in patients treated with IVIG. In spite of such controversy surrounding the use of IVIG in idiopathic and immune-related RSM, most treating physicians have continued to offer IVIG as a last resort/ reserve therapy. In our experience, in Kuwait, IVIG has resulted in successful pregnancies in selected patients, especially those patients with secondary RSM. Some of the researchers $[137,138]$ who have reported that IVIG has no benefits in RSM have indicated that IVIG is beneficial in patients with secondary RSM and could be offered to selected patients with RSM.

The treating physician who is challenged by the many desperate patients presenting with high-order and idiopathic RSM frequently falls back to IVIG as a reserve therapy. I agree that immune therapy should not be offered routinely to women with RSM outside formal research studies, a principle that we adhere to in our clinics in Kuwait. Patients who present with unexplained RSM should be offered tender loving care, psychological support as well as dedicated intensive monitoring and comprehensive care and they should be reassured that a successful future pregnancy could be in the range of $75 \%[19$, $62,142]$. Efforts have been intensified to find an appropriate therapy for patients with idiopathic RSM. It should be recalled that in about $50-60 \%$ of patients presenting with RSM, in spite of comprehensive investigations, no aetiological factor is identified, and these are classified as unexplained or idiopathic RSM. Therapy for these cases of idiopathic RSM remains a great challenge and increases the state of quagmire which the treating physicians are confronting on a regular basis. Therapy for many of these patients is empirical, and psychological support and tender loving care are part of the treatment offered to the patients in dedicated RSM clinics; this approach is strictly implemented in our clinic in Kuwait and has been supported by several studies $[19,62,141,143]$ which have reported beneficial effects. Many of the patients with unexplained RSM have also been offered empirical treatment with LDA and/or heparin (unfractionated heparin or LMWH) in the hope that live births may follow and
Diejomaoh 
pregnancy outcome is enhanced. This treatment modality is frequently used by many treating physicians, also in Kuwait, and all efforts to advise against this line of treatment have been unfruitful. Recent randomized controlled trials $[2,5,45,125,144]$ have indicated that interventions with the drugs stated above do not improve live birth rates in women with unexplained/idiopathic RSM. As clearly recommended $[2,5]$, empirical treatment of patients with unexplained RSM with the drugs stated above should be resisted and discontinued, and I strongly support these views and restate that in spite of the challenges we face in finding suitable evidence-based therapy for our patients with RSM, we should resist offering empirical treatment. IVIG should continue to be used in research-based RSM clinics, which may ultimately provide research data to strengthen the use of IVIG and other drugs.

One of the major setbacks in the field of the management and research in RSM is the lack of large, well-conducted, double-blinded, randomized, placebo-controlled and preferably multi-centred trials with well-defined objectives and dealing with patients with standardized definitions of RSM. It will be of immense benefit if research is encouraged in the areas covered above, and researchers should stick to the more universally accepted definition of 3 or more consecutive miscarriages before 20 weeks' gestation. There is a need to emphasize the call for intensive research in the areas of the immunological basis of RSM (especially in the large unresolved entity of unexplained RSM), the role of NK cells and cytokines in RSM, the use of IVIG in RSM (an area of therapy I strongly believe should be explored in greater detail), and the trial of newer treatment modalities for RSM. The role of PGD in the management of recurrent early miscarriages when other forms of therapy have been unsuccessful, especially missed miscarriages, should be explored as a research modality for RSM management.

\section{Conclusion}

RSM is a formidable and challenging diagnostic and therapeutic clinical quagmire for the treating physician and a distressing and psychological problem for the presenting patient, affecting 1-2\% of women in their reproductive years. The aetiology is diverse and varied, with parental karyotype disorders, uterine anatomic abnormalities, and APS being the most frequently diagnosed causes. The aetiology is unknown, idiopathic or unexplained in $40-60 \%$ of patients. Immunological factors and undiagnosed chromosome abnormalities may be the underlying cause of idiopathic RSM. Extensive investigations should be performed in all patients. APS has been confirmed as an established aetiological factor in about $20 \%$ of patients, while results of the tests for uterine abnormalities and congenital thrombophilia should be interpreted with caution. Other diagnostic tests such as screening for NK cells should only be undertaken in research-based clinics. The management of RSM is quite varied and challenging. The use of LDA and heparin, an established treatment for APS, has been associated with a live birth rate of $54-74 \%$ ( $82 \%$ in some reports). The role of such a therapy in congenital thrombophilia remains controversial. Surgical treatment for uterine anatomical disorders requires further studies. The management of idiopathic RSM remains a clinical quagmire, and although psychological care has been associated with a favourable outcome, the empirical use of LDA and heparin and/or intravenous immunoglobulin, which have been applied in these patients by many treating physicians, should be discouraged because available results do not support this line of management. There is a need for larger, randomized, double-blinded, multi-centred, placebo-controlled studies to establish an evidence-based basis for the aetiology, diagnosis and treatment of RSM, and the definition of RSM should be standardized in such studies.

\section{Acknowledgement}

I am grateful to all my colleagues in the Department of Obstetrics and Gynaecology, Kuwait University, and at the Maternity Hospital, Kuwait, and to all other colleagues in the private and Ministry of Health hospitals/clinics in Kuwait for their referrals and for allowing me to study and treat their patients. I would also like to express my gratitude to my nursing staff and all my patients for their contribution. I am greatly indebted to Madam Asiya T. Mohammed and all the technical and administrative staff of the Department of Obstetrics and Gynaecology, Faculty of Medicine, Kuwait University, for all their support.

\section{Disclosure Statement}

The authors have no conflicts of interest to disclose.
Recurrent Spontaneous Miscarriage Is Still Challenging and Controversial
Med Princ Pract 2015;24(suppl 1):38-55 DOI: $10.1159 / 000365973$ 


\section{References}

-1 McNamee K, Dawood F, Farquharson R: Recurrent miscarriage and thrombophilia: an update. Curr Opin Obstet Gynecol 2012;24: 229-234.

2 Royal College of Obstetricians and Gynaecologists: The Use of Antithrombotics in the Prevention of Recurrent Pregnancy Loss. Scientific Advisory Committee Opinion Paper 26. London, RCOG Press, 2011.

$>3$ Jauniaux E, Farquharson RG, Christiansen $\mathrm{OB}$, et al: Evidence-based guidelines for the investigation and medical treatment of recurrent miscarriage. Hum Reprod 2006;21:22162222.

44 Christiansen OB, Nybo Anderson AM, Bosch $\mathrm{E}$, et al: Evidence-based investigations and treatments of recurrent pregnancy loss. Fertil Steril 2005;83:821-839.

5 Royal College of Obstetricians and Gynaecologists: The Investigation and Treatment of Couples with Recurrent First-Trimester and Second-Trimester Miscarriages. Green-Top Guideline No. 17. London, RCOG Press, 2011.

-6 Duckitt K, Qureshi A: Recurrent miscarriage. Clin Evid 2011;2:1409.

7 Coulam CB: Epidemiology of recurrent spontaneous abortion. Am J Reprod Immunol 1991;26:23-27.

-8 Shapira E, Ratzon R, Shoham-Vardi I, et al: Primary vs secondary recurrent pregnancy loss - epidemiological characteristics, etiology and next pregnancy outcome. J Perinat Med 2012;40:389-396.

9 Bashiri A, Gete S, Mazor M, et al: Recurrent pregnancy loss - evaluation and treatment. Harefuah 2011;150:852-856, 875.

10 Stirrat GM: Recurrent miscarriage. Lancet 1990;336:673-675.

11 American Society for Reproductive Medicine: Patient Fact Sheet: Recurrent Pregnancy Loss. Birmingham, American Society for Reproductive Medicine, 2008.

$>12$ Jaslow CR, Carney JL, Kutteh WH: Diagnostic factors identified in 1,020 women with two versus three or more recurrent pregnancy losses. Fertil Steril 2010;93:1234-1243.

$>13$ Cohn DM, Goddijn M, Middeldorp S, et al: Recurrent miscarriage and antiphospholipid antibodies: prognosis of subsequent pregnancy. J Thromb Haemost 2010;8:2208-2213.

14 American College of Obstetrics and Gynecologists Committee on Practice Bulletins: ACOG Practice Bulletin. Paper 40. Obstet Gynecol 2011.

$>15$ Diejomaoh M, Jirous J, Al-Azemi M, et al: Insulin resistance in women with recurrent spontaneous miscarriage of unknown aetiology. Med Princ Pract 2007;16:114-118.

16 Patel BG, Lessey BA: Clinical assessment and management of the endometrium in recurrent early pregnancy loss. Semin Reprod Med 2011;29:491-506
17 Lachmi-Epstein A, Mazor M, Bashiri A: Psychological and mental aspects and 'tender loving care' among women with recurrent pregnancy losses. Harefuah 2012;151:633637,654 .

18 Nybo Anderson AM, Wohlfahrt J, Christens $\mathrm{P}$, et al: Maternal age and fetal loss: population based register linkage study. BMJ 2000;320: 1708-1712.

19 Bringham SA, Conlon C, Farquharson RG: A longitudinal study of pregnancy outcome following idiopathic recurrent miscarriage. Hum Reprod 1999;14:2868-2871.

20 Reagan L, Braude PR, Trembath PL: Influence of past reproductive performance on risk of spontaneous abortion. BMJ 1989;299:541545.

21 De la Rochebrochard E, Thonneau P: Paternal age and maternal age are risk factors of miscarriage: results of a multicenter European study. Hum Reprod 2002;17:1649-1656.

22 Metwally M, Saravelos SH, Ledger WL, et al: Body mass index and risk of miscarriage in women with recurrent miscarriage. Fertil Steril 2010;94:290-295.

23 Metwally M, Ong KJ, Ledger WL, et al: Does high body mass index increase the risk of miscarriage after spontaneous and assisted conception? A meta-analysis of the evidence. Fertil Steril 2008;90:714-726.

24 Lashen H, Fear K, Sturdee DW: Obesity is associated with increased risk of first trimester and recurrent miscarriage: matched casecontrol study. Hum Reprod 2004;19:16441646.

25 van der Berg MMJ, van Maarle MC, van Wely $\mathrm{M}$, et al: Genetics of early miscarriage. Biochim Biophys Acta 2012;1822:1951-1959.

26 De Braekeleer M, Dao TN: Cytogenic studies in couples experiencing repeated pregnancy losses. Hum Reprod 1990;5:519-528.

27 Clifford K, Rai R, Watson H, et al: An informative protocol for the investigation of recurrent miscarriage: preliminary experience of 500 consecutive cases. Hum Reprod 1994;9: 1328-1332.

28 Stephenson MD, Sierra S: Reproductive outcomes in recurrent pregnancy loss associated with a parental carrier of structural chromosome rearrangement. Hum Reprod 2006;21: 1076-1082.

29 Franssen MT, Korevaar JC, van der Veen F, et al: Reproductive outcome after chromosome analysis in couples with two or more miscarriages: index (corrected)-control study. BMJ 2006;332:759-763, erratum in BMJ 2006;332: 1012.

-30 Alijotas-Reig J, Garrido-Gimenez C: Current concepts and new trends in the diagnosis and management of recurrent miscarriage. Obstet Gynecol Surv 2013;68:445-466.

$>31$ Brezina PR, Kearns WG: The evolving role of genetics in reproductive medicine. Obstet Gynecol Clin North Am 2014;41:41-55.
32 Brezina PR, Kutteh WH: Classic and cuttingedge strategies for the management of early pregnancy loss. Obstet Gynecol Clin North Am 2014;41:1-18.

33 Salim R, Regan L, Woelfer B, et al: A comparative study of the morphology of congenital uterine anomalies in women with and without a history of recurrent first trimester miscarriage. Hum Reprod 2003;18:162-166.

34 Grimbizis GF, Camus M, Tarlatzis BC, et al: Clinical implications of uterine malformations and hysteroscopic treatment: results. Hum Reprod Update 2001;7:161-174.

35 Homer HA, Li TC, Cooke ID: The septate uterus: a review of management and reproductive outcome. Fertil Steril 2000;73:1-14.

36 Woelfer B, Salim R, Bannerjee S, et al: Reproductive outcomes in women with congenital uterine anomalies detected by three-dimensional ultrasound screening. Obstet Gynecol 2001;98:1099-1103.

-37 Sugiura-Ogasawara M, Ozaki Y, Suzumori N: Mullerian anomalies and recurrent miscarriage. Curr Opin Obstet Gynecol 2013;25: 293-298.

38 De Wolf F, Carreras LO, Moerman P, et al: Decidual vasculopathy and extensive placental infarction in a patient with repeated thromboembolic accidents, recurrent fetal loss and lupus anticoagulant. Am J Obstet Gynecol 1982;142:829-834.

39 Rai RS, Reagan L, Clifford K, et al: Antiphospholipid antibodies and beta-2-glycoproteinI in 500 women with recurrent miscarriage: results of a comprehensive screening approach. Hum Reprod 1995;10:2001-2005.

40 Lockwood CJ, Romero R, Feinberg RF, et al: The prevalence and biologic significance of lupus anticoagulant and anticardiolipin antibodies in a general obstetric population. Am J Obstet Gynecol 1989;161:369-373.

41 Pattison NS, Chamley LW, McKay EJ, et al: Antiphospholipid antibodies in pregnancy: prevalence and clinical association. Br J Obstet Gynaecol 1993;100:909-913.

42 Ernest JM, Marshburn PB, Kutteh WH: Obstetric antiphospholipid syndrome: an update on pathophysiology and management. Semin Reprod Med 2011;29:522-539.

43 Kutteh WH, Rote NS, Silver R: Antiphospholipid antibodies and reproduction: the antiphospholipid antibody syndrome. Am J Reprod Immunol 1999;41:133-152.

44 Schust DJ, Hill JA: Recurrent Pregnancy Loss. Philadelphia, Lippincott Williams and Wilkins, 2002.

-45 Kaandorp SP, Goddijn M, van der Post JA, et al: Aspirin plus heparin alone in women with recurrent miscarriage. N Engl J Med 2010; 362:1586-1596.

46 McNamee K, Dawood F, Farquharson RG: Thrombophilia and early pregnancy loss. Best Pract Res Clin Obstet Gynaecol 2012;26:91102. 
-47 Larsen EC, Christiansen OB, Kolte AM, et al: New insights into mechanisms behind miscarriage. BMC Med 2013;11:154.

-48 Robertson L, Wu O, Langhorne P, et al: Thrombophilia in pregnancy: a systematic review. Br J Haematol 2006;132:171-196.

-49 Lund M, Nielsen HS, Hviid TV: Hereditary thrombophilia and recurrent pregnancy loss: a retrospective cohort study of pregnancy outcome and complications. Hum Reprod 2010;25:2978-2984.

50 Silver RM, Zhao Y, Spong CY, et al: Prothrombin gene G20210A mutation and obstetric complications. Obstet Gynecol 2010; 115:14-20.

51 Sabadell J, Castellas M, Alijotas-Reig J, et al: Inherited antithrombin deficiency and pregnancy: maternal and fetal outcome. Eur J Obstet Gynecol Reprod Biol 2010;149:47-51.

52 Kovalevsky G, Gracia CR, Berlin JA, et al: Evaluation of the association between hereditary thrombophilias and recurrent pregnancy loss: a meta-analysis. Arch Intern Med 2004; 164:558-563.

53 Jivraj S, Markris M, Saravelos S, et al: Pregnancy outcome in women with factor $\mathrm{V}$ Leiden and recurrent miscarriage. Br J Obstet Gynaecol 2009;116:995-998.

54 Rai R, Backos M, Elgaddal S, et al: Factor V Leiden and recurrent miscarriage - prospective outcome of untreated pregnancies. Hum Reprod 2002;17:442-445.

55 Carp H, Dolitzky M, Tur-Kaspa I, et al: Hereditary thrombophilias are not associated with a decreased live birth rate in women with recurrent miscarriage. Fertil Steril 2002;78: 58-62.

- 56 Abalovich M, Gutierrez S, Alcaraz G, et al: Overt and subclinical hypothyroidism complicating pregnancy. Thyroid 2002;12:63-68.

57 Mills JL, Simpson H, Driscoll SG, et al: Incidence of spontaneous abortion among normal women and insulin-dependent diabetic women whose pregnancies were identified within 21 days of conception. N Engl J Med 1988;319:1617-1623.

58 Li TC, Spuijbroek MD, Tuckerman E, et al: Endocrinological and endometrial factors in recurrent miscarriage. Br J Obstet Gynaecol 2000;107:1471-1479.

59 Bussen S, Sutterlin M, Steck T: Endocrine abnormalities during the follicular phase in women with recurrent spontaneous abortion. Hum Reprod 1999;14:18-20.

60 Diejomaoh MF, Al-Azemi M, Jirous J, et al: Thyroid autoantibodies have no impact on pregnancy in women with recurrent miscarriage. ACOG abstract. Obstet Gynecol 2006; 107:98S.

61 Rushworth FH, Backos M, Rai R, et al: Prospective pregnancy outcome in untreated recurrent miscarriages with thyroid autoantibodies. Hum Reprod 2000;15:1637-1639.

62 Clifford K, Rai R, Reagan L: Future pregnancy outcome in unexplained recurrent first trimester miscarriage. Hum Reprod 1997;12: 387-389.
63 Royal College of Obstetricians and Gynaecologists: The Management of Recurrent Miscarriage. Guidelines 17. London, RCOG Press, 1998, pp 1-10.

64 Diejomaoh MFE, Al-Azemi M, Jirous J, et al: The aetiology and pattern of recurrent pregnancy loss. J Obstet Gynaecol 2002;22:62-67.

65 Diejomaoh M, Jirous J, Al-Azemi M, et al: The relationship of recurrent spontaneous miscarriage with reproductive failure. Med Princ Pract 2003;12:107-111.

66 Cocksedge KA, Saravellos SH, Metwally M, et al: How common is polycystic ovary syndrome in recurrent miscarriage? Reprod Biomed Online 2009; 19:572-576.

67 Craig LB, Ke RW, Kutteh WH: Increased prevalence of insulin resistance in women with a history of recurrent pregnancy loss. Fertil Steril 2002;78:487-490.

68 Diejomaoh M, Jirous J, Al-Azemi M, et al: Insulin resistance in women with recurrent miscarriage of unknown aetiology. Med Princ Pract 2007;16:114-118.

69 Wang Y, Zhao H, Li Y, et al: Relationship between recurrent miscarriage and insulin resistance. Gynecol Obstet Invest 2011;72:245251.

70 Lee RM, Silver RM: Recurrent pregnancy loss: summary and clinical recommendations. Semin Reprod Med 2000;18:433-440.

-71 Dosiou C, Giudice LC: Natural killer cells in pregnancy and recurrent pregnancy loss. Endocrine and immunologic perspectives. Endocr Rev 2005;26:44-62.

72 Moffett A, Reagan L, Braude P: Natural killer cells, miscarriage and infertility. BMJ 2004; 329:1283-1285.

73 Cooper MA, Fehniger TA, Caligiur MA: The biology of human natural killer cell subsets. Trends Immunol 2001;22:633-640.

74 Tang AW, Alfiveric Z, Quenby S: Natural killer cells and pregnancy outcomes in women with recurrent miscarriage and infertility: a systemic review. Hum Reprod 2011;26:19711980.

75 Nagler A, Lanier LL, Cwirla S, et al: Comparative studies of human FcRIII-positive and negative natural killer cells. J Immunol 1989; 143:3183-3191

76 King A, Balendran N, Wooding P, et al: CD3 leukocytes present in the human uterus during early placentation: phenotypic and morphologic characterization of the CD56++ population. Dev Immunol 1991;1:169-190.

77 Beer AE, Kwak JY, Ruiz JE: Immunophenotypic profiles of peripheral blood lymphocytes in women with recurrent pregnancy losses and infertile women with failed in-vitro fertilization cycles. Am J Reprod Immunol 1996;35:376-382.

78 Gregory CD, Lee H, Rees GB, et al: Natural killer cells in normal pregnancy: analysis using monoclonal antibodies and single cell cytotoxicity assays. Clin Exp Immunol 1987;62: 121-127.
79 Lachapelle MH, Miron P, Hemmings R, et al: Endometrial T, B, and NK cells in patients with recurrent spontaneous abortion. Altered profile and pregnancy outcome. J Immunol 1996;156:4027-4034.

-80 Nitrivalas EI, Kwam-Kim JYH, Gilman-Sachs A, et al: Status of peripheral blood natural killer cells in women with recurrent spontaneous abortions and infertility of unknown aetiology. Hum Reprod 2001;16:855-861.

81 Kwak JYH, Beaman KD, Gilman-Sachs A, et al: Up-regulated expression of CD56+, CD56+/CD16+ and CD19+ cells in peripheral blood lymphocytes in pregnant women with recurrent spontaneous abortions. Am J Reprod Immunol 1995;34:93-99.

82 Gilman-Sachs A, Du Chateau BK, Aslakson CJ, et al: Natural killer (NK) cell subsets and NK cell cytotoxicity in women with histories of recurrent spontaneous abortions. Am J Reprod Immunol 1999;41:99-105.

83 Chaout G, Ledee-Bataille N, Zourbass S: Cytokines, implantation and early abortion: reexamining the Th1/Th2 paradigm leads to question in the single pathway. Single therapy concept. Am J Reprod Immunol 2003;50: 177-186.

84 Chaout G, Ledee-Bataille N, Dubanchet S, et al: Reproductive immunology 2003: reassessing the Th1/Th2 paradigm. Immunol Lett 2004;92:207-214.

85 Wegman TG, Lin H, Guilbert L, et al: Bidirectional cytokine interaction in the maternalfetal relationship: is successful pregnancy a Th2 phenomenon? Immunol Today 1993; 14: 353-356.

86 Daher S, Mattar R, Gueuvoghlanian-Silva BY, et al: Genetic polymorphisms and recurrent spontaneous abortions: an overview of current knowledge. Am J Reprod Immunol 2012; 67:341-347.

87 Reagan L, Jivraj S: Infection and pregnancy loss; in Maclean AB, Reagan L, Carrington D (eds): Infection and Pregnancy. London, RCOG Press, 2001, pp 291-304.

88 Summers PR: Microbiology relevant to recurrent miscarriage. Clin Obstet Gynecol 1994; 37:722-729.

89 Diejomaoh MFE, Rotimi VO, Omu AE, et al: Correlation between bacterial vaginosis and adverse pregnancy outcome. Med Princ Pract 1999;8:167-254.

90 Rotimi VO, Diejomaoh FME, Omu AE, et al: The prevalence of bacterial vaginosis and vaginosis-associated pathogens in pregnant women in Kuwait. Kuwait Med J 1999;31: 251-256.

91 Leitich H, Kiss H: Asymptomatic bacterial vaginosis and intermediate flora as risk factors for adverse pregnancy outcome. Best Pract Res Clin Obstet Gynaecol 2007;21:375390.

92 Hay PE, Lamont RF, Taylor-Robinson D, et al: Abnormal bacterial colonisation of the genital tract and subsequent preterm delivery and late miscarriage. BMJ 1994;308:295298.
Recurrent Spontaneous Miscarriage Is Still Challenging and Controversial
Med Princ Pract 2015;24(suppl 1):38-55 DOI: $10.1159 / 000365973$ 
$\$ 93$ Brocklehurst $\mathrm{P}$, Hannah M, McDonald H: Interventions for treating bacterial vaginosis in pregnancy. Cochrane Database Syst Rev 2000;CD000262.

94 Robert JM, Macara LM, Chalmers EA, et al: Inter-assay variations in antiphospholipid antibody testing. Br J Obstet Gynaecol 2002; 109:348-349.

95 van Dunne FM, Doggen CJ, Heemskerk M, et al: Factor V Leiden mutation in relation to fecundity and miscarriage in women with venous thrombosis. Hum Reprod 2005;20: 802-806.

96 Beaman KD, Ntrivalas E, Mallers TM, et al: Immune etiology of recurrent pregnancy loss and its diagnosis. Am J Reprod Immunol 2012;67:319-325.

97 Royal College of Obstetricians and Gynaecologists: The Investigation and Treatment of Couples with Recurrent Miscarriage. Guideline No. 17. London, RCOG Press, 2003.

98 Reagan L, Rai R, Backos M, et al: Recurrent miscarriage and parental karyotype abnormalities: prevalence and future pregnancy outcome. Abstracts of the 17th Annual Meeting of the ESHRE, Lausanne, Switzerland, 2001. Hum Reprod 2001;16(suppl 1):177-178.

\$9 Fransen MT, Musters AM, van der Veen F, et al: Reproductive outcome after PGD in couples with recurrent miscarriage carrying a structural chromosome abnormality: a systematic review. Hum Reprod Update 2011; 17:467-475.

100 Lalioti MD: Can preimplantation genetic diagnosis overcome recurrent pregnancy failure? Curr Opin Obstet Gynecol 2008;20: 199-204.

101 Ogilvie CM, Braude P, Scriven P: Successful pregnancy outcomes after preimplantation genetic diagnosis (PGD) for carriers of chromosome translocations. Hum Fertil (Camb) 2001;4:168-171.

102 Scriven PN, Flinter FA, Braude PR, et al: Robertsonian translocations - reproductive risks and indications for preimplantation genetic diagnosis. Hum Reprod 2001;16:2267-2273.

103 Kowalik CR, Goddijn M, Emanuel MH, et al: Metroplasty versus expectant management for women with recurrent miscarriage and a septate uterus. Cochrane Database Syst Rev 2011;6:CD008576.

104 Gibbs DM, Salaria DA: Transabdominal cervicoisthmic cerclage in the management of recurrent second trimester miscarriage and preterm delivery. Br J Obstet Gynaecol 1995; 102:802-806.

105 Anthony GS, Walker RG, Cameron AD, et al: Transabdominal cervico-isthmic cerclage in the management of cervical incompetence. Eur J Obstet Gynecol Reprod Biol 1997;72:127-130.

106 Debbs RH, DeLa Vega GA, Pearson S, et al: Transabdominal cerclage after comprehensive evaluation of women with previous unsuccessful transvaginal cerclage. Am J Obstet Gynecol 2007;197:317.e1-e4.
107 Zaveri V, Aghajafari F, Amankwah K, et al: Abdominal versus vaginal cerclage after a failed transvaginal cerclage: asystematic review. Am J Obstet Gynecol 2002;187:868872.

108 Thuesen LL, Dines BR, Langhoff-Roos J: Pre-pregnancy transabdominal cerclage. Acta Obstet Gynecol Scand 2009;88:483486.

109 Rai R, Regan L: Recurrent miscarriage. Lancet 2006;368:601-611.

110 Miyakis S, Lockshin MD, Atsumi T, et al: International consensus statement on an update of the classification criteria for definite antiphospholipid syndrome (APS). J Thromb Haemost 2006;4:295-306.

111 Practice Committee of the American Society for Reproductive Medicine: Evaluation and treatment of recurrent pregnancy loss: a committee opinion. Fertil Steril 2012;98: 1103-1111.

112 Bates SM, Greer IA, Pabinger I, et al; American College of Chest Physicians: Venous thromboembolism, thrombophilia, antithrombolic therapy and pregnancy: American College of Chest Physicians EvidenceBased Clinical Practice Guidelines (8th Edition). Chest 2008;133:844S-886S.

113 Empson MB, Lassere M, Craig JC, et al: Prevention of recurrent miscarriage for women with antiphospholipid antibody or lupus anticoagulant. Cochrane Database Syst Rev 2005;CD002859.

114 Maki A, Cheung WW, Cheak AA, et al: Combination of heparin and aspirin is superior to aspirin alone in enhancing births in patients with recurrent pregnancy loss and positive antiphospholipid antibodies: a meta-analysis of randomized controlled trials and meta-regression. Rheumatology (Oxford) 2010;49:281-288.

115 Diejomaoh MFE, Al-Azemi MM, Bandar A, et al: A favorable outcome of pregnancies in women with primary and secondary recurrent pregnancy loss associated with antiphospholipid syndrome. Arch Gynecol Obstet 2002;266:61-66.

116 American College of Obstetricians and Gynecologists: Committee on Practice Bulletins-Obstetrics: ACOG Practice Bulletin No. 118: antiphospholipid syndrome. Obstet Gynecol 2011;117:192-199.

117 Noble LS, Kutteh WH, Lashey N, et al: Antiphospholipid antibodies associated with recurrent pregnancy loss: prospective, multicenter, controlled pilot study comparing treatment with low molecular weight heparin versus unfractionated heparin. Fertil Steril 2005;83:684-690.

118 Stephenson MD, Ballem PJ, Tsang P, et al: Treatment of antiphospholipid antibody syndrome (APS) in pregnancy: a randomized pilot trial comparing low molecular weight heparin to unfractionated heparin. J Obstet Gynaecol Can 2004;26:729-734.
119 Farquharson RG, Quenby S, Greaves M: Antiphospholipid syndrome in pregnancy: a randomized, controlled trial of treatment. Obstet Gynecol 2002;100:408-413.

120 Laskin CA, Spitzer KA, Clark CA, et al: Low molecular weight heparin and aspirin for recurrent pregnancy loss: results from the randomized controlled HepASA Trial. J Rheumatol 2009;36:279-287.

121 Rai R, Cohen H, Dave M, et al: Randomised controlled trial of aspirin and aspirin plus heparin in pregnant women with recurrent miscarriage associated with phospholipid antibodies (or antiphospholipid antibodies). BMJ 1997;314:253-257.

122 Ogueh O, Chen MF, Spurll G, et al: Outcome of pregnancy in women with hereditary thrombophilia. Int J Gynaecol Obstet 2001; 74:247-253.

123 Carp H, Dolitzky M, Inbal A: Thromboprophylaxis improves the live birth rate in women with consecutive recurrent miscarriages and hereditary thrombophilia. J Thromb Haemost 2003;1:443-448.

124 Brenner B, Hoffman R, Carp H, et al: Efficacy and safety of two doses of enoxaparin in women with thrombophilia and recurrent pregnancy loss: the LIVE-ENOX study. J Thromb Haemost 2005;3:227-229.

125 Viser J, Ulander VM, Helmerhorst FM, et al: Thromboprophylaxis for recurrent miscarriage in women with or without thrombophilia. HABENOX: a randomised multicenter trial. J Thromb Haemost 2010;105: 295-301.

126 Royal College of Obstetricians and Gynaecologists: Cervical Cerclage. Green-Top Guideline No. 60. London, RCOG Press, 2011.

127 Drakeley AJ, Roberts D, Alfirevic Z: Cervical cerclage for prevention of preterm delivery: meta-analysis of randomized trials. Obstet Gynecol 2003;102:621-627, erratum in Obstet Gynecol 2004;103:201.

128 Berghella V, Odibo AO, To MS, et al: Cerclage for short cervix on ultrasonography: meta-analysis of trials using individual patient-level data. Obstet Gynecol 2005;106: 181-189.

129 Csapo AL, Pulkien MO, Ruttner B, et al: The significance of the human corpus luteum in pregnancy maintenance. Am J Obstet Gynecol 1972;112:1061-1067.

130 Goldstein P, Berrier J, Rosen HS, et al: A meta-analysis of randomized control trials of progestational agents in pregnancy. $\mathrm{Br} \mathrm{J} \mathrm{Ob-}$ stet Gynaecol 1989;96:265-274.

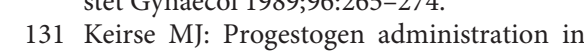
pregnancy may prevent preterm delivery. A meta-analysis. Br J Obstet Gynaecol 1990;97: 149-158.

132 Raghupathy R, Al-Muttawa E, Al-Azemi M, et al: Progesterone-induced blocking factor (PIBF) modulates cytokine production by lymphocytes from women with recurrent miscarriage or preterm delivery. J Reprod Immunol 2009;80:91-99. 
133 Haas DM, Ramsey PS: Progesterone for preventing miscarriage. Cochrane Database Syst Rev 2008;2:CD003511.

134 Omar MH, Mashifa MK, Lim PS, et al: Dydrogesterone in threatened abortion: pregnancy outcome. J Steroid Biochem Mol Biol 2005;97:421-425.

135 El-Zibdeh MY: Dydrogesterone in the reduction of recurrent spontaneous abortion. J Steroid Biochem Mol Biol 2005;97:431-434.

136 Porter TF, LaCoursiere Y, Scott JR: Immunotherapy for recurrent miscarriage. Cochrane Database Syst Rev 2006;CD0000112.

137 Stephenson MD, Kutteh WH, Purkiss S, et al: Intravenous immunoglobulin and idiopathic secondary recurrent miscarriage: a multicentered randomized placebo controlled trial. Hum Reprod 2010;25:2203-2209.
138 Ata B, Tan SL, Shehata F, et al: A systematic review of intravenous immunoglobulin for treatment of unexplained recurrent miscarriage. Fertil Steril 2011;96:1080-1085.

139 Christiansen OB, Pedersen B, Rosgaard A, et al: A randomized double-blind, placebo controlled trial of intravenous immunoglobulin in the prevention of recurrent miscarriage: evidence of a therapeutic effect in women with secondary recurrent miscarriage. Hum Reprod 2002;17:809-816.

140 Perricone R, Di Muzio G, Perricone C, et al: High levels of peripheral blood NK cells in women suffering from recurrent spontaneous abortion are reverted from high-dose intravenous immunoglobulin. Am J Reprod Immunol 2006;55:232-239.

141 Coulam CB, Acacia B: Does immunotherapy for treatment of reproductive failure enhance live births? Am J Reprod Immunol 2012;67:296-303
142 Stray-Pedersen B, Stray-Pedersen S: Etiological factors and subsequent reproductive performance in 195 couples with a prior history of habitual abortion. Am J Obstet Gynecol 1984;148:140-146.

143 Liddel HS, Pattison NS, Zanderigo A: Recurrent miscarriage - outcome after supportive care in early pregnancy. Aust NZ J Obstet Gynaecol 1991;31:320-322.

144 Clark P, Walker ID, Langhorne PC, et al: Scottish pregnancy intervention study (SPIN) collaborators. SPIN (Scottish Prevention Intervention) study: a multicenter, randomized controlled trial of low-molecular weight heparin and low-dose aspirin in women with recurrent miscarriage. Blood 2010;115:4162-4167. 